\title{
Development of a new Long Path Absorption Photometer (LOPAP) instrument for the sensitive detection of $\mathrm{NO}_{2}$ in the atmosphere
}

\author{
G. Villena, I. Bejan, R. Kurtenbach, P. Wiesen, and J. Kleffmann \\ Bergische Universität Wuppertal, Physikalische Chemie, Germany
}

Received: 16 December 2010 - Published in Atmos. Meas. Tech. Discuss.: 14 March 2011

Revised: 7 July 2011 - Accepted: 25 July 2011 - Published: 29 August 2011

\begin{abstract}
A compact and simple instrument for the sensitive detection of $\mathrm{NO}_{2}$ in the atmosphere has been developed. $\mathrm{NO}_{2}$ is sampled in a stripping coil by a selective chemical reaction, converted into a highly absorbing dye, which is detected by long path absorption in a liquid core waveguide. Several interferences were quantified in the laboratory which so far can all be neglected. The significant interferences against $\mathrm{HONO}$ and $\mathrm{O}_{3}$ were suppressed by using an upstream $\mathrm{HONO} / \mathrm{O}_{3}$-scrubber. The instrument has a detection limit of 2 pptv, an accuracy of $10 \%$ and a precision of $0.5 \%$ for 3 min time resolution. Thus, the new $\mathrm{NO}_{2}$-LOPAP technique is more sensitive than known commercial $\mathrm{NO}_{2}$ instruments. The new analyzer is much simpler to apply than other highly sensitive and selective $\mathrm{NO}_{2}$ methods, e.g. LIF or REMPI methods. The new instrument allows an absolute calibration that can be easily performed with liquid nitrite standards, which is a significant advantage compared with other $\mathrm{NO}_{2}$ measurement techniques for which $\mathrm{NO}_{2}$ calibration gas mixtures are typically necessary. The new instrument has been validated against the chemiluminescence technique during an urban field campaign and against the FTIR technique in a smog chamber under complex photosmog conditions. The data sets exhibit high correlation and excellent agreement.
\end{abstract}

\section{Introduction}

Nitrogen oxides $\left(\mathrm{NO}_{\mathrm{x}}=\mathrm{NO}+\mathrm{NO}_{2}\right)$ are important trace species that are emitted into the atmosphere from both, natural and anthropogenic sources, the latter being dominated by road transport (Vestreng et al., 2009 and references therein).

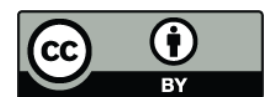

Correspondence to: J. Kleffmann (kleffman@uni-wuppertal.de)
$\mathrm{NO}_{2}$ affects the oxidation capacity of the atmosphere through its direct participation in the formation of $\mathrm{O}_{3}$ and nitrous acid (HONO), which through their photolysis are major sources of the $\mathrm{OH}$ radical, the detergent of the atmosphere. In addition, by its reaction with the $\mathrm{OH}$ radical, $\mathrm{NO}_{2}$ also limits radical concentrations in the polluted atmosphere. $\mathrm{NO}_{2}$ contributes to acid precipitation and formation of other atmospheric oxidants such as the nitrate radical, $\mathrm{NO}_{3}$ (Crutzen, 1979; Finlayson-Pitts and Pitts, 2000; Seinfeld and Pandis, 2006). The range of $\mathrm{NO}_{2}$ concentrations varies from few pptv in remote areas to more than $100 \mathrm{ppbv}$ in polluted regions (Finlayson-Pitts and Pitts, 2000).

$\mathrm{NO}_{2}$ is also of importance due to its health impacts on both, short term and long-term exposures of the population, however, it is difficult to separate its health effect from other pollutants such as particulate matter (Samoli et al., 2006; Delfino et al., 2008; Mol et al., 2008). In addition, all these health studies may be affected by the non-selective detection of $\mathrm{NO}_{2}$ for the techniques applied (Spicer et al., 2001; Brunekreef, 2001; Van Strien et al., 2004; Jarvis et al., 2005).

During the last two decades, the European Union (EU) set different legislative frameworks in order to assess and manage air quality and to control the pollutants released in vehicle exhaust, e.g. EU Directives 96/62/EC, 98/69/EC, 99/96/EC and 99/30/EC (First Daughter Directive). European $\mathrm{NO}_{\mathrm{x}}$ emissions linked to road transport have strongly decreased during the last $20 \mathrm{yr}$. However, unexpectedly, $\mathrm{NO}_{2}$ is not showing the same tendency, either $\mathrm{NO}_{2}$ levels are constant or even show a small increase (EEA, 2007; Vestreng et al., 2009). Thus, for European urban network stations it will be difficult in the near future to meet the annual mean limit value for $\mathrm{NO}_{2}$ of $40 \mu \mathrm{g} \mathrm{m}^{-3}$ (Carslaw et al., 2007). The reasons for this $\mathrm{NO}_{2}$ behaviour can be explained in terms of secondary formation in the atmosphere and by increasing primary $\mathrm{NO}_{2}$ emissions. The latter is due to increasing number of diesel cars and the introduction of new exhaust

Published by Copernicus Publications on behalf of the European Geosciences Union. 
technologies, which oxidize a portion of $\mathrm{NO}$ to $\mathrm{NO}_{2}$ in order to promote the oxidation of soot collected on the particle filter (Grice et al., 2009). Due to this increase of primary $\mathrm{NO}_{2}$ emissions many studies have been focused on its impact on air quality in the urban environment (Carslaw and Beevers, 2004, 2005a, b; Carslaw, 2005; AQEG, 2007; Carslaw et al., 2007; Carslaw and Carslaw, 2007; Jenkin et al., 2008; Alvarez et al., 2008; Keuken et al., 2009).

Due to its importance in atmospheric chemistry and air quality, many direct or indirect techniques have been developed for measuring $\mathrm{NO}_{2}$ in the laboratory and/or in the field. Spectroscopic methods such as Differential Optical Absorption Spectroscopy (DOAS) (Platt et al., 1979; Edner et al., 1993; Thornton et al., 2003), Laser Induced Fluorescence (LIF) (Thornton et al., 2000; Matsumoto et al., 2001, 2006; Dari-Salisburgo et al., 2009; Fuchs et al., 2010), Cavity Ring Down Spectroscopy (CRDS) (Mazurenka et al., 2003; Hargrove et al., 2006; Osthoff et al., 2006; Fuchs et al., 2009, 2010), Incoherent Broad Band Cavity Enhanced Absorption Spectroscopy (IBBCEAS) (Gherman et al., 2008; Wu et al., 2009; Fuchs et al., 2010), Cavity Attenuated Phase shift Spectroscopy (CAPS) (Kebabian et al., 2005, 2008), Tunable Diode Laser Absorption Spectroscopy (TDLAS) (Gregory et al., 1990; Li et al., 2004; Herndon et al., 2004), and Resonance Enhanced MultiPhoton Ionization (REMPI) (Garnica et al., 2000; McKeachie et al., 2001) have been used for $\mathrm{NO}_{2}$ detection, with some of them reaching very low detections limits (e.g. REMPI, LIF).

Simpler chemiluminescence techniques are typically used for measuring $\mathrm{NO}_{2}$. One of these is the luminolchemiluminescence method (Wendel et al., 1983), which employs the reaction between $\mathrm{NO}_{2}$ and an alkaline solution of luminol resulting in light emission. This technique is direct, but it is non-specific for $\mathrm{NO}_{2}$ because ozone and peroxyacylnitrates (PANs) are also detected (Fehsenfeld et al., 1990). The most widely used chemiluminescence technique is based on the gas phase reaction between $\mathrm{NO}$ and $\mathrm{O}_{3}$ forming an electronically excited molecule of $\mathrm{NO}_{2}^{*}$ that emits light, which is proportional to the NO concentration. To detect also $\mathrm{NO}_{2}$, either heated $\left(300-350^{\circ} \mathrm{C}\right)$ molybdenum (Mo) surfaces (Fontjin et al., 1970; Ridley and Howlett, 1974) or photolytic $\mathrm{NO}_{2}$ converters (Kley and McFarland, 1980) are applied. The reduction of $\mathrm{NO}_{2}$ to $\mathrm{NO}$ by heated Mo converters followed by ozone reaction is the reference method recommended by the US EPA (Demerjian, 2000) and by the European legislation (European Standard, EN 14211, 2005), but is affected by significant interferences against other reactive nitrogen species $\left(\mathrm{NO}_{\mathrm{y}}\right)$ like $\mathrm{N}_{2} \mathrm{O}_{5}, \mathrm{HONO}, \mathrm{HNO}_{3}$, PAN, etc., which are also reduced to NO (Winer et al., 1974; Dunlea et al., 2007). The conversion of $\mathrm{NO}_{2}$ into $\mathrm{NO}$ by photolytic converters, for which either Xenon lamps or UV emitting diodes ("blue light converters") are used, are much more selective, although positive interferences by photolysis of HONO for the Xenon lamp converter instruments (Rohrer et al., 2005) and negative interferences in the presence of hy- drocarbons have been reported (Kurtenbach et al., 2001; Kleffmann et al., 2001; Bejan et al., 2006; Villena et al., 2011). In addition, photolytic converter instruments exhibit non linear response for high $\mathrm{NO}_{2}$ and $\mathrm{O}_{3}$ levels caused by the reaction $\mathrm{NO}$ with $\mathrm{O}_{3}$ in the converter. Finally, all $\mathrm{NO} / \mathrm{O}_{3}$ chemiluminescence instruments show a negative $\mathrm{H}_{2} \mathrm{O}$ interference by quenching of the excited $\mathrm{NO}_{2}^{*}$ during the $\mathrm{NO}$ detection.

Caused by the non-selective detection of $\mathrm{NO}_{2}$ in most commercial instruments, the development of a simple instrument for reliable $\mathrm{NO}_{2}$ measurements is of high importance. Accordingly, in the present study a new $\mathrm{NO}_{2}$-LOPAP instrument (Long Path Absorption Photometer), which is based on the Saltzman reaction (Saltzman, 1954) is described. The instrument is designed to be easy to use, sensitive and compact for continuously measuring $\mathrm{NO}_{2}$ under all experimental conditions both, in the atmosphere but also in laboratory and in smog chamber experiments.

\section{Experimental section}

The $\mathrm{NO}_{2}$-LOPAP instrument consists of two separate units. (1) The external sampling unit which is directly situated at the sampling site (i.e. in the atmosphere) and thus avoiding the use of any sampling lines. (2) The detection unit (19" instrument) where the azodye, which is formed in the sampling unit, is detected using long path absorption. The system is furthermore designed as a two-channel system for correction of possible interferences (Fig. 1).

\subsection{Sampling unit}

In the external sampling unit three glass stripping coils are used in series. In the first coil ("HONO/O ${ }_{3}$-scrubber": 24 turns; $35 \mathrm{~mm}$ average turn diameter; $1.6 \mathrm{~mm}$ inner tube diameter) interfering $\mathrm{HONO}$ and $\mathrm{O}_{3}$ are removed from the air stream, without significant uptake of $\mathrm{NO}_{2}$. This separation from $\mathrm{NO}_{2}$ is made with a stripping solution that contains $10 \mathrm{~g} \mathrm{l}^{-1}$ sulphanilamide, $0.6 \mathrm{gl}^{-1}$ potassium indigotrisulphonate in $158 \mathrm{~g} \mathrm{l}^{-1}$ acetic acid, in which HONO and ozone are quantitatively removed. Ozone efficiently reacts with Indigo (Bader and Hoigné, 1981):

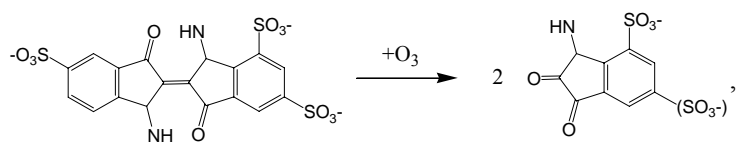

while HONO is transformed into a diazonium salt:

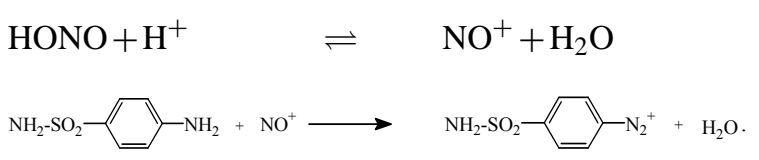

Besides $\mathrm{HONO}$ and $\mathrm{O}_{3}, 4 \%$ of the $\mathrm{NO}_{2}$ is also collected in this scrubber solution, which is corrected in the data evaluation. Through this $\mathrm{HONO} / \mathrm{O}_{3}$-scrubber the known 


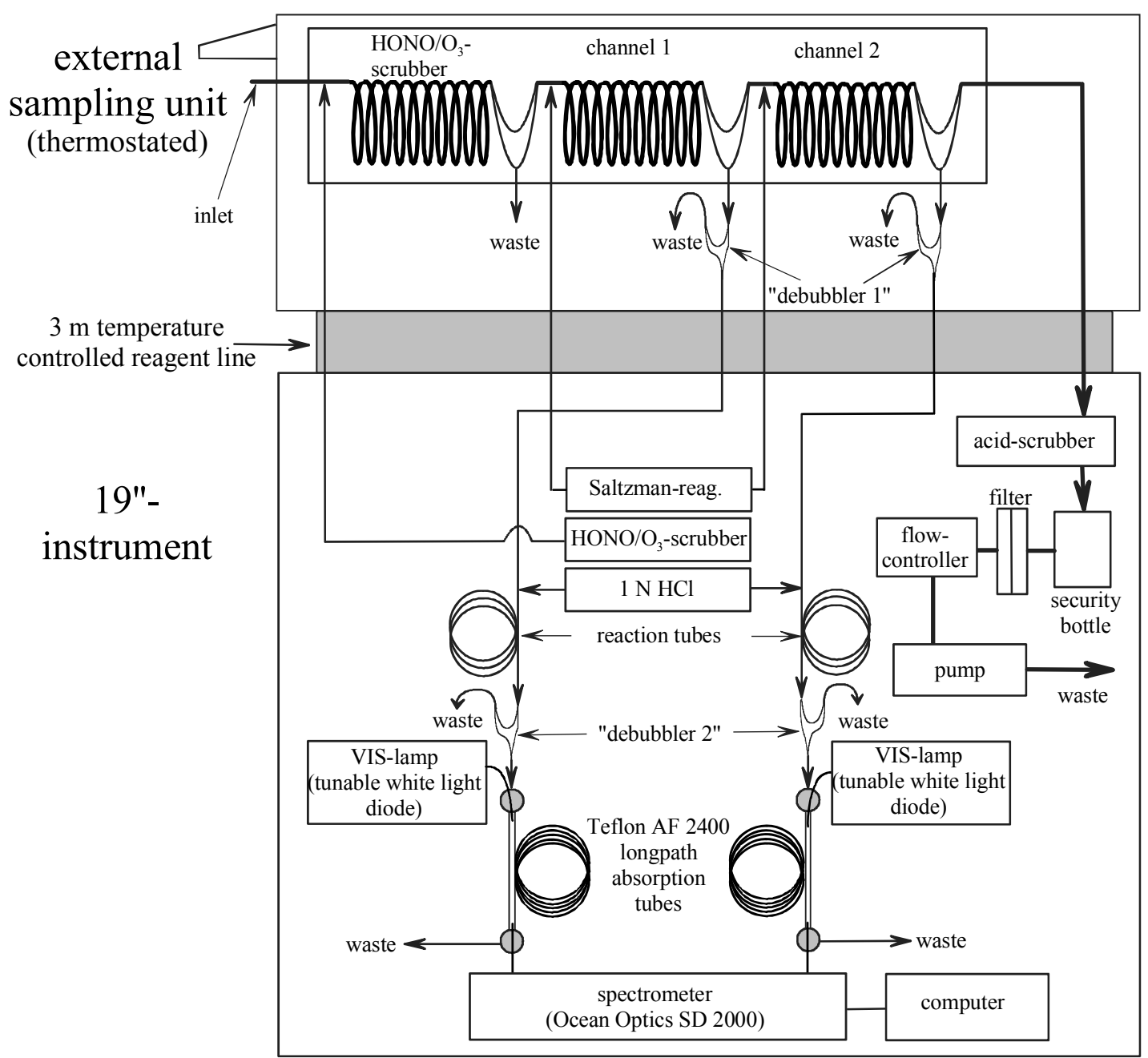

Fig. 1. Schematic setup of the $\mathrm{NO}_{2}$-LOPAP instrument.

HONO (Milani and Dasgupta, 2001) and ozone interferences (Adema, 1979) by the Griess-Saltzman reaction are suppressed.

$\mathrm{NO}_{2}$ and other potential interferences are collected in the second stripping-coil (Channel 1), while potential interferences are measured in the third coil (Channel 2). Both coils have similar dimension than the $\mathrm{HONO} / \mathrm{O}_{3}$-scrubber. The gas phase is sucked with a membrane pump through the stripping-coils, a security flask with electrical control, a Teflon membrane filter and a mass flow controller. The gas flow through the stripping-coils is $0.51 \mathrm{~min}^{-1}$. As sampling solution a modified Griess-Saltzman Reagent (N-(1naphtyl)ethylenediamine dihydrochloride (NEDA) $1 \mathrm{gl}^{-1}$, sulphanilamide $7 \mathrm{gl}^{-1}, 84 \mathrm{gl}^{-1}$ acetic acid, $3 \mathrm{gl}^{-1} \mathrm{NH}_{3}$ $25 \%, \mathrm{pH}=3$ ) is used. By the reaction of $\mathrm{NO}_{2}$ with the sampling solution an intensive coloured azodye is formed (Saltzman, 1954), the mechanism of which is not completely understood. It was postulated that $\mathrm{NO}_{2}$ first reacts with water (Saltzman, 1954):
$2 \mathrm{NO}_{2}+\mathrm{H}_{2} \mathrm{O} \quad \longrightarrow \quad \mathrm{HONO}+\mathrm{HNO}_{3}\left(\right.$ or $\left.\mathrm{NO}_{3}^{-}\right)$.

The formed HONO further reacts according to reactions (2) and (3) forming the diazonium salt, which reacts with NEDA forming an intensively coloured azodye:

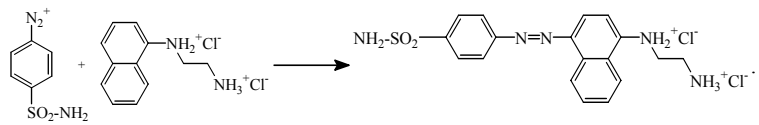

Based on reaction (4) a maximum dye yield of $50 \%$ is expected, which is however observed only for very high concentrations of $\mathrm{NO}_{2}$ in the higher ppmv-range; whereas at atmospheric concentrations yields near $100 \%$ have been measured (Huygens and Lanting, 1975). The yield of the overall reaction (amount of dye/ $\mathrm{NO}_{2}$ absorbed) is expressed in the literature as so-called "Saltzman factor" (Huygens and Lanting, 1975). The high Saltzman factor and the observed dependency of the sampling efficiency on the NEDA concentration and the $\mathrm{pH}$ (see Sects. 3.1.2 and 3.1.3) shows that at 
low $\mathrm{NO}_{2}$ concentrations reaction (4) is of minor importance. Instead, it is proposed here that $\mathrm{NO}_{2}$ oxidizes partly deprotonated NEDA leading to quantitative formation of HONO:

$\mathrm{NO}_{2}+\mathrm{NEDA} \longrightarrow \mathrm{HONO}+$ products

Analogue redox reactions in the liquid phase are also known for other organic compounds, such as phenols and alkenes (Alfassi et al., 1986; Pryor and Lightsey, 1981). Instead of reaction (6), Saltzman originally postulated a reaction of $\mathrm{NO}_{2}$ with sulphanilamide (Saltzman, 1954). However this can be ruled out based on the results obtained with the HONOLOPAP instrument (Heland et al., 2001; Kleffmann et al., 2002). With this instrument no significant reaction between the sampling solution containing $10 \mathrm{~g}^{-1}$ sulphanilamide and $\mathrm{NO}_{2}$ could be observed.

The thermostated stripping coils $\left(15^{\circ} \mathrm{C}\right)$, which are connected to the detection unit through an isolated reagent line are located in the external sampling unit directly at the sampling site. Thus, line effects, for example heterogeneous reactions of $\mathrm{NO}_{2}$ or the gas phase reaction between $\mathrm{NO}$ and $\mathrm{O}_{3}$, can be neglected.

\subsection{Detection unit (19" instrument)}

After the transfer of the sampling reagent from the external sampling unit to the instrument, the sampling solution is mixed with $1 \mathrm{~N} \mathrm{HCl}$ (ratio 1:1) in order to convert all $\mathrm{HONO}$, originating from reaction (6), into $\mathrm{NO}^{+}$, reaction (2). Furthermore, the addition of $\mathrm{HCl}$, increases the refraction index of the solution and in consequence increases the light intensity in the absorption tubes. Finally, NEDA precipitates slowly with time on the surface of the absorption tubes, which leads to a reduction of the measured light intensity. This is also reduced by the addition of $\mathrm{HCl}$.

A downstream reaction volume with residence time $\geq 1$ min guarantees a quantitative formation of the dye. Before entering the detection unit, potential air bubbles are separated from the sampling solution ("debubbler 2", see Fig. 1), since bubbles would deteriorate the stability of the light signal. The detection unit is basically composed of a special flexible Teflon tube (DuPont, Teflon AF 2400; $0.6 \mathrm{~mm}$ i.D.; $0.8 \mathrm{~mm}$ o.d.; variable length, here: $1.4 \mathrm{~m}$ and $2.4 \mathrm{~m}$ used). Visible light (LUXEON, warm white LED, Typ: LXHL-MWGC) is focused into the tubing via fibre optics. With the refractive index of the tubing material being lower $\left(n_{\mathrm{AF} 2400}: \sim 1.29\right)$ than that of the solution of the dye, the light - depending on the angle of incidence - undergoes multiple total reflection on the inner walls of the tubing and stays inside the liquid for absorption (Yao et al., 1998). The intensity of the diodes can be regulated without change of the spectral distribution (pulsed power supply unit: QUMA Elektronik \& Analytik GmbH). On the opposite end of this so-called liquid core waveguide, LCW, the light is collected again by a glass fibre and detected with a two channel grating mini-spectrometer using a diode array detector (Ocean
Optics, SD 2000). The absorption spectra of both channels averaged over a variable time interval are stored on a mini computer for later analysis. In addition, the absorption of the azodye can be continuously monitored for variable absorption wavelengths (see Sect. 2.3).

A two channel system is used for the quantification of possible interferences. With this arrangement, two stripping coils are connected in series (see Fig. 1). In Channel 1, $\mathrm{NO}_{2}$ is almost quantitatively taken up as well as potentially interfering compounds, whereas in Channel 2 - under the assumption of a low uptake of the interferences - only the interferences are collected. $\mathrm{NO}_{2}$ concentrations can be calculated from the difference between both channels considering the sampling efficiency of $\mathrm{NO}_{2}$ in Channel 1.

\subsection{Data evaluation}

To be independent from intensity fluctuations, which are caused by e.g. temperature changes and/or bubbles of air entering the tubing, no so-called background $\left(I_{0}\right)$ spectra without absorption of the dye are used for data evaluation. Instead, the logarithm of the ratio of two intensities taken at different wavelengths in the same measured spectrum is a more stable and robust measure of the azodye concentration. These two intensities are taken (a) at the absorption maximum near $544 \mathrm{~nm}$ or a neighbouring wavelength, $I_{\mathrm{abs}}$, and (b) at a wavelength where no azodye absorption occurs, $I_{\text {ref }}$, e.g. at $\lambda_{\text {ref }}$ of $650 \mathrm{~nm}$. Knowing that $I_{\text {ref }}$ is directly proportional to the background intensity $I_{0}$ at the absorption wavelength, $\lambda_{\text {abs }}$, the logarithm of $\left(I_{\text {ref }} / I_{\text {abs }}\right)$ becomes a linear measure of the concentration $c$ according to Lambert-Beers law:

$\mathrm{A}^{*}=\log \left(I_{\mathrm{ref}} / I_{\mathrm{abs}}\right)=k_{\lambda} \times l \times c+\log \left(I_{\mathrm{ref}} / I_{0}\right)$.

Where $l$ denotes the absorption path length and $k_{\lambda}$ is the absorption coefficient of the azodye, which is ca. $5 \times 10^{4} 1 \mathrm{~mol}^{-1} \mathrm{~cm}^{-1}$ at $544 \mathrm{~nm}$ (Grasshoff et al., 1983). The intercept of Eq. (7) depends mainly on the chosen absorption and reference wavelengths and may show variations, which are due to different purities of the reagents. Accordingly, zero air measurements have to be performed regularly during the operation of the instrument and a calibration of the two channels with a liquid nitrite standard is mandatory when the reagents have been renewed.

\section{Results and discussion}

\subsection{Instrument parameters optimization}

\subsubsection{Sampling reagents}

Originally, bubblers are used for the detection of $\mathrm{NO}_{2}$ with the Griess-Saltzman reagent, which however can not be used for continuous detection of $\mathrm{NO}_{2}$. Instead a stripping coil is 


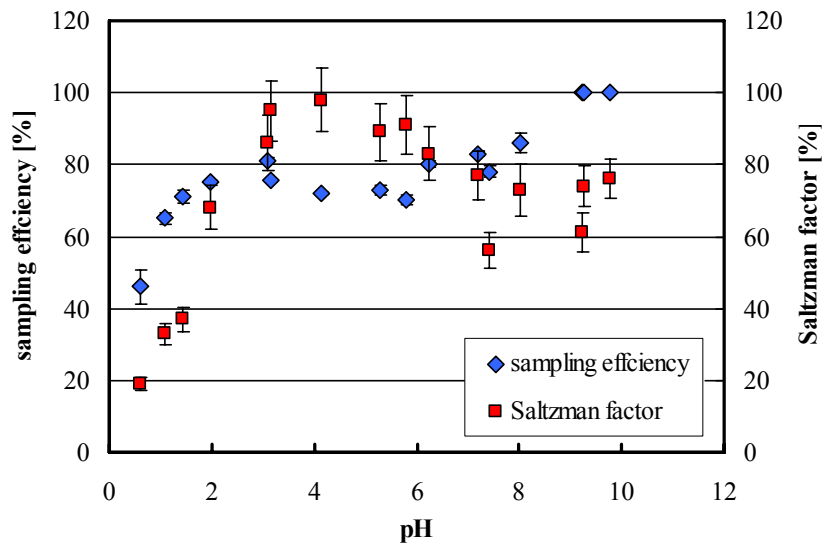

Fig. 2. Variation of the sampling efficiency and the Saltzman factor with $\mathrm{pH}$. Griess- Saltzman reagent: $1 \mathrm{gl}^{-1}$ NEDA, $5 \mathrm{gl}^{-1}$ sulphanilamide, $7.2 \mathrm{~g} \mathrm{l}^{-1} \mathrm{HCl}$ was used here instead of acetic acid, $\mathrm{pH}$ adjusted by the addition of $\mathrm{NH}_{3}$. Air flow $=1000 \mathrm{ml} \mathrm{min}^{-1}$, liquid flow $=0.27 \mathrm{ml} \mathrm{min}^{-1}$.

used in the present instrument, for which, however, the gasliquid contact time is much shorter. Thus, to obtain a high sampling efficiency of $\mathrm{NO}_{2}$ and a high Saltzman factor, a modified sampling reagent has to be used. In the present study, the sampling efficiency is defined as the proportion of $\mathrm{NO}_{2}$ incorporated in the second stripping coil (Channel 1) with respect to the total quantity of $\mathrm{NO}_{2}$ entering this coil. The Saltzman factor is calculated based on the proportion of the generated amount of dye in channel 1 with respect to the quantity of $\mathrm{NO}_{2}$ absorbed in this channel. A high sampling efficiency is required for a correction of possible interferences using the two channel system. A low Saltzman factor causes a production of $\mathrm{NO}$ as a co-product that should be avoided for a possible future extension of the instrument for NO detection. Thus, both factors need to be as high as possible. For the optimization of the instrument several dependencies of the sampling reagent were investigated.

\section{Variation of the $\mathrm{pH}$}

The $\mathrm{pH}$ of the sampling solution leads to a strong variation of the sampling efficiency as well as of the Saltzman factor (see Fig. 2).

The sampling efficiency increases up to $\mathrm{pH}=3$, gets constant up to $\mathrm{pH}=7$ and reaches $100 \%$ at higher $\mathrm{pH}$. This can be explained by the reaction of $\mathrm{NO}_{2}$ with NEDA (6) for which the deprotonated form of NEDA reacts faster than the protonated form. This effect was also observed in the reaction of $\mathrm{NO}_{2}$ with phenols in the liquid phase (Ammann et al., 2005). Thus, the two steps in the sampling efficiency can be explained by the neutralization of the two $-\mathrm{NH}_{3}^{+}$groups of NEDA. The Saltzman factor increases strongly up to $\mathrm{pH}=$ 4 , however starts to decline at higher $\mathrm{pH}$. Based on the $\mathrm{pH}$ dependency, a pH of 3-4 is recommended for which both the

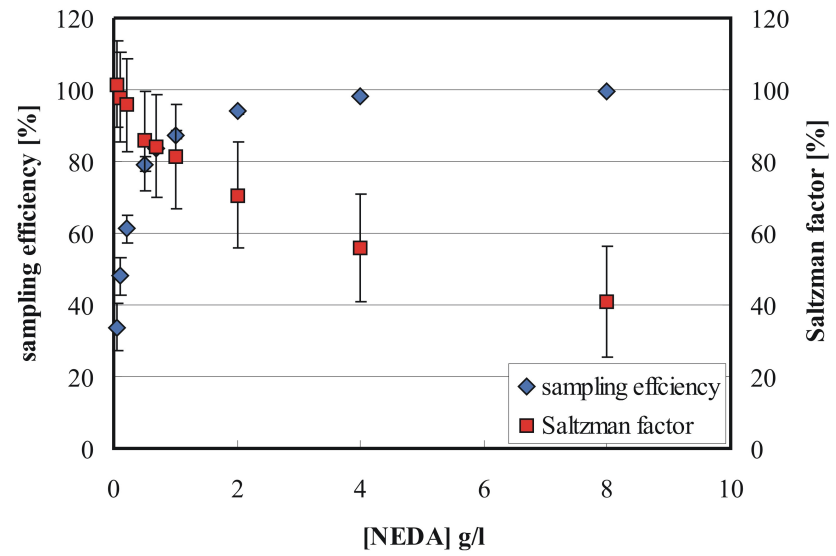

Fig. 3. Variation of the sampling efficiency and the Saltzman factor with the NEDA concentration. Griess-Saltzman reagent: $7 \mathrm{~g}^{-1}$ sulphanilamide, $84 \mathrm{gl}^{-1}$ acetic acid, $\mathrm{pH}=3$, adjusted with $\mathrm{NH}_{3}$. Air flow $=650 \mathrm{ml} \mathrm{min}^{-1}$, liquid flow $=0.35 \mathrm{ml} \mathrm{min}^{-1}$.

sampling efficiency and the Saltzman factor are high. Higher $\mathrm{pH}$ leads to a higher sampling efficiency but to a lower Saltzman factor. In addition, stronger interferences against PANs are expected with increasing $\mathrm{pH}$ (Frenzel et al., 2000) and therefore should be avoided.

\section{Variation of the NEDA concentration}

Increasing NEDA concentration leads to a strong increase of the sampling efficiency, reaching $100 \%$ for high NEDA concentrations (Fig. 3).

From the strong NEDA dependence, it is proposed that $\mathrm{NO}_{2}$ is directly reacting with NEDA, reaction (6), whereas the reactions with water (4) and sulphanilamide can be neglected. However, at the same time, a decrease of the Saltzman factor is observed. Parallel measurements with a NO chemiluminescence instrument demonstrated an undesirable formation of NO as a co-product. Caused by the NEDA and $\mathrm{pH}$ dependencies observed for the Saltzman factor it is proposed that $\mathrm{NO}^{+}$formed by reactions (6) and (2) can also react with NEDA to generate NO:

$\mathrm{NO}^{+}+\mathrm{NEDA} \quad \longrightarrow \quad \mathrm{NO}+$ products.

Based on the undesirable NO formation and the possible future extension of the instrument for NO detection, the NEDA concentration should not be too high and is limited here to $\leq 1 \mathrm{gl}^{-1}$.

\section{Variation of the sulphanilamide concentration}

Whereas the concentration of sulphanilamide has almost no effect on the sampling efficiency of $\mathrm{NO}_{2}$, an increasing Saltzman factor is observed for increasing sulphanilamide concentration (Fig. 4). 


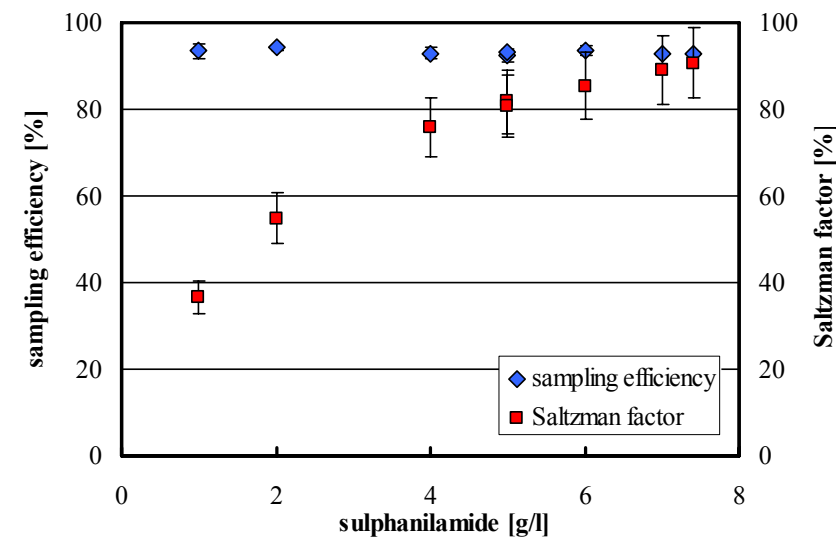

Fig. 4. Variation of the sampling efficiency and the Saltzman factor with the sulphanilamide concentration. Griess-Saltzman Reagent: $1.6 \mathrm{gl}^{-1}$ NEDA, $\mathrm{pH}=3$, adjusted with $\mathrm{NH}_{3}$. Air flow $=1000 \mathrm{ml} \mathrm{min}^{-1}$, liquid flow $=0.2 \mathrm{ml} \mathrm{min}^{-1}$.

Table 1. Optimized composition of the Griess-Saltzman reagent $(\mathrm{pH}=3)$.

\begin{tabular}{lc}
\hline Reagent & conc. $\left[\mathrm{g}^{-1}\right]$ \\
\hline N-(1-naphtyl)ethylenediamine & 1 \\
dihydrochloride (NEDA) & 7 \\
sulphanilamide & 84 \\
acetic acid & 3 \\
$\mathrm{NH}_{3}(25 \%)$ & \\
\hline
\end{tabular}

This behaviour can be explained by a NEDA limited uptake of $\mathrm{NO}_{2}$ by reaction (6), and a sulphanilamide limited further conversion of HONO into the diazonium salt via reactions (2) and (3). It is proposed that the relative high $\mathrm{pH}$ used leads to slow kinetics of reactions (2) and (3) and thus, the low Saltzman factor can be explained by the secondary reaction (8). With increasing sulphanilamide concentration, the rate of reaction (3) increases and parallel reaction (8) becomes of minor importance. Caused by the maximum solubility of sulphanilamide in water, only concentrations up to $7.5 \mathrm{~g} \mathrm{l}^{-1}$ were studied here. However, the solubility can be increased by the addition of higher concentrations of acetic acid. In the present study $7 \mathrm{gl}^{-1}$ sulfanilamide in $84 \mathrm{gl}^{-1}$ acetic acid is finally used.

The optimized composition of the Griess-Saltzman solution is summarized in Table 1.

\subsubsection{Improvement of the sampling conditions}

\section{Length of the stripping-coil}

Stripping coils with different lengths were used (10, 20, 25 turns, $22 \mathrm{~mm}$ average turn diameter, $2.4 \mathrm{~mm}$ i.d.), which were similar to those used in the previous HONO- and $\mathrm{HNO}_{3}$ -
LOPAP instruments (Kleffmann et al., 2002, 2007). Due to the slow uptake of $\mathrm{NO}_{2}$ only the longest coil could be used for $\mathrm{NO}_{2}$. Furthermore, because high NEDA concentrations were not applied (see Sect. 3.1.3), the maximum sampling efficiency obtained with the longest coil was only $95 \%$. In addition, caused by the low gas flow applied, high volume of sampling reagent accumulated in the stripping coil leading to a lower time resolution of the instrument. Thus, a new coil with smaller inner diameter, higher surface to volume (S/V) ratio and higher gas velocity was used in order to improve the sampling efficiency and time resolution. This new coil with 24 turns, $35 \mathrm{~mm}$ average turn diameter and $1.6 \mathrm{~mm}$ inner diameter, increases the sampling efficiency to $97 \%$ and leads to a better time resolution.

\section{Variation of the sampling temperature}

The temperature was varied in the range $5-30^{\circ} \mathrm{C}$. Only a small increase of the sampling efficiency and a minor decrease of the Saltzman factor were observed with increasing temperature. For practical reasons a sampling temperature of $15^{\circ} \mathrm{C}$ was chosen to avoid condensation of water in the gas line to the instrument.

\section{Variation of the liquid flow}

The variation of the liquid flow has only a slight effect on the sampling efficiency and the Saltzman factor for values $>0.1 \mathrm{ml} \mathrm{min}^{-1}$. This can be explained by a surface limited uptake of $\mathrm{NO}_{2}$ by which the fast reaction (6), see Sect. 3.1.3 $\left(k_{\mathrm{NO}_{2}+\mathrm{NEDA}}=(3.6 \pm 1.6) \times 10^{6} \mathrm{M}^{-1} \mathrm{~s}^{-1}\right)$ and the low solubility of $\mathrm{NO}_{2}$ leads to a liquid diffusion limited uptake of $\mathrm{NO}_{2}$. In contrast, for a limitation of the $\mathrm{NO}_{2}$ uptake by any slow reaction in the liquid phase the sampling efficiency should increase with increasing liquid flow. Caused by the missing liquid flow dependency, the time resolution and the sensitivity of the instrument can be varied by the liquid flow without influencing other parameters.

\section{Variation of the gas flow}

The gas flow variation has a strong effect on the Sampling efficiency but not on the Saltzman factor. The variation of the sampling efficiency can be well described by a first order uptake kinetics of reaction (6), which is expected for a heterogeneous multiphase reaction, which is limited by the low solubility and the liquid phase diffusion of $\mathrm{NO}_{2}$ (see Sect. 3.1.6). In contrast, the Saltzman factor is only affected by the slower consecutive chemistry in the liquid phase, which is dependent only on the composition of the sampling solution, but not on the gas/liquid contact time. Based on all the observations described up to now, a surface limited $\mathrm{NO}_{2}$ uptake 
Table 2. Summary of the parameters of the $\mathrm{NO}_{2}$-LOPAP instrument.

\begin{tabular}{ll}
\hline parameters: & \\
\hline air flow & $0.51 \mathrm{~min}^{-1}$ \\
liquid flow (stripping solution) & $0.2-0.4 \mathrm{ml} \mathrm{min}-1$ \\
absorption path length & $1.4 / 2.4 \mathrm{~m}(0.1-6 \mathrm{~m}$ possible $)$ \\
range of $\lambda$ abs & $550-610 \mathrm{~nm}$ \\
sampling efficiency & $97 \%$ \\
Saltzman factor & $95 \%$ \\
measurement range & $0.002-300 \mathrm{ppbv}$ \\
time resolution (10-90\%) & $\approx 3-6 \mathrm{~min}$ \\
precision & $\pm(0.5 \%+\mathrm{DL})$ \\
accuracy & $\pm(10 \%+\mathrm{DL})$ \\
detection limit (DL) & $2 \mathrm{pptv}(3 \mathrm{~min}$ time resolution) \\
\hline
\end{tabular}

is proposed, which is improved by increasing the $\mathrm{S} / \mathrm{V}$ ratio of the stripping coil and increasing the gas/liquid contact time. Thus, a maximum gas flow of only $0.51 \mathrm{~min}^{-1}$ is recommended for the used stripping coils (see Table 2).

\subsubsection{Determination of the liquid phase rate coefficient of $\mathrm{NO}_{2(\mathbf{l q})}+\mathrm{NEDA}_{(\mathbf{l q})}$}

In order to calculate the second order rate coefficient of the liquid-phase reaction between $\mathrm{NO}_{2}$ and NEDA, reactive uptake coefficients $\left(\gamma_{\mathrm{NO}_{2}}\right)$ of $\mathrm{NO}_{2}$ were determined for the applied stripping coil. The reactive uptake coefficient is the probability of the permanent uptake of a molecule that hits the liquid surface and can be limited by several processes such as gas phase diffusion, mass accommodation $(\alpha)$, solubility, liquid diffusion and reaction in the liquid phase. Gas phase diffusion limitation will be of minor importance for the observed uptake coefficients even for laminar flow (Murphy and Fahey, 1987) and can be further neglected caused by the turbulent flow conditions in a stripping coil. The independence of $\gamma_{\mathrm{NO}_{2}}$ on the liquid flow (see above), the linear dependence of $\gamma \mathrm{NO}_{2}$ with the square root of the NEDA concentration (see Fig. 5) and the known low solubility of $\mathrm{NO}_{2}$ in water shows that the uptake is limited by diffusion in the liquid phase. Similar to the study of Ammann et al. (2005) the second order rate constant $k_{\mathrm{NO}_{2}+\mathrm{NEDA}}$ can be calculated from the slope of a plot of $\gamma \mathrm{NO}_{2}$ against [NEDA] $]^{1 / 2}$ according to Eq. (9):

$$
\gamma / \mathrm{NO}_{2}=\frac{4 \times \mathrm{H}_{\mathrm{NO}_{2}} \times R \times T \times \sqrt{k_{\mathrm{NO}_{2}+\mathrm{NEDA}} \times[\mathrm{NEDA}] \times D_{\mathrm{NO}_{2}}}}{\langle c\rangle},
$$

in which $\mathrm{H}_{\mathrm{NO}_{2}}$ is the $\mathrm{NO}_{2}$ Henry's law constant $\left(1.6 \times 10^{-2} \mathrm{M} \mathrm{atm}^{-1}\right.$ at $288 \mathrm{~K}$, calculated using the expression from Squadrito and Postlethwait, 2009), $\langle c\rangle$ is the mean thermal molecular velocity $\left(364 \mathrm{~m} \mathrm{~s}^{-1}\right.$ at $\left.288 \mathrm{~K}\right), R$ is the gas constant $\left(8.314 \mathrm{~J} \mathrm{M}^{-1} \mathrm{~K}^{-1}\right), T$ the temperature and $D_{\mathrm{NO}_{2}}$ is the aqueous phase diffusion coefficient $\left(1.1 \times 10^{-5} \mathrm{~cm}^{2} \mathrm{~s}^{-1}\right.$ at $288 \mathrm{~K}$, Cheung et al., 2000; Komiyama and Inoue, 1980).

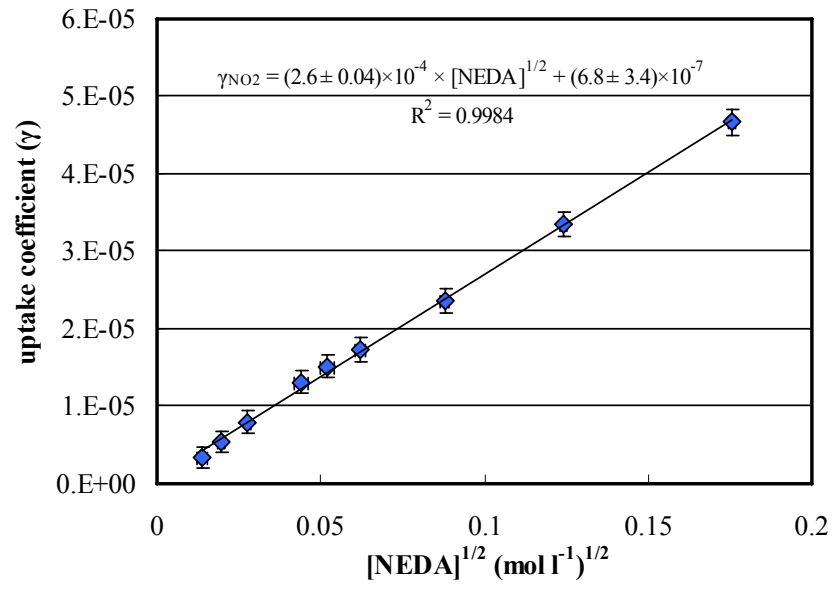

Fig. 5. $\mathrm{NO}_{2}$ uptake coefficients as a function of $[\mathrm{NEDA}]^{1 / 2}$ at $288 \mathrm{~K}$. Griess-Saltzman Reagent: $7 \mathrm{~g} \mathrm{l}^{-1}$ sulphanilamide, $84 \mathrm{~g} \mathrm{l}^{-1}$ acetic acid, $\mathrm{pH}=3$, adjusted with $\mathrm{NH}_{3}$. Air flow $=650 \mathrm{ml} \mathrm{min}^{-1}$, liquid flow $=0.35 \mathrm{ml} \mathrm{min}^{-1}$.

From the slope of the plot shown in Fig. 5 a rate coefficient $k_{\mathrm{NO}_{2}+\mathrm{NEDA}}=(3.6 \pm 1.6) \times 10^{6} \mathrm{M}^{-1} \mathrm{~s}^{-1}$ has been determined using Eq. (9).

A similar value of $k_{\mathrm{NO}_{2}+\mathrm{NEDA}}$ was also determined using higher concentrations of sulphanilamide $\left(10 \mathrm{~g} \mathrm{l}^{-1}\right)$ and acetic acid $\left(158 \mathrm{~g}^{-1}\right)$. Accordingly, it is proposed that the reaction only depends on the NEDA concentration.

From the intercept of the linear regression in Fig. 5 a $\mathrm{NO}_{2}$ uptake coefficient $\left(\gamma \mathrm{NO}_{2}\right)$ on the used acetic acid/sulphanilamide solution of $7 \times 10^{-7}$ has been derived, which is slightly higher than the value of $\sim 10^{-7}$ reported for the uptake of $\mathrm{NO}_{2}$ on pure water by Ammann et al. (2005).

\subsubsection{Instrument parameters}

The detection limit, the response time, i.e. the time the instrument needs to rise from $10 \%$ to $90 \%$ of the full signal and the measurement range of the LOPAP instrument are strongly dependent on several factors such as (a) the sample gas flow rate, (b) the liquid flow rate, and (c) the length of the absorption tubes.

The theoretical sensitivity of the instrument will increase linearly with the gas flow rate and/or the absorption lengths as well as by decreasing the liquid flow rate. In practice, these parameters are limited, e.g. by a decreasing $\mathrm{NO}_{2}$ sampling efficiency with increasing gas flow rate, so that up to now the air flow is limited to $0.51 \mathrm{~min}^{-1}$. Light intensity as well as time resolution decrease when the absorption path length is increased, so that a maximum length of $6 \mathrm{~m}$ can be used (Kleffmann and Wiesen, 2008). However so far, only optical path lengths of 1.4 and $2.4 \mathrm{~m}$ have been applied in the present study. The sensitivity can be increased by decreasing the liquid flow, however, the time resolution of the instrument is then reduced. For the applied liquid flows of 


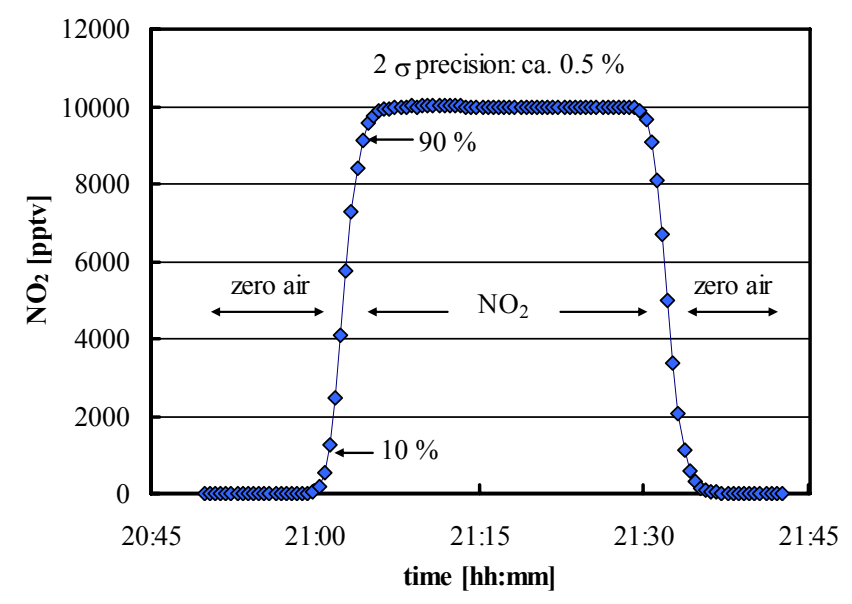

Fig. 6. Time resolution $(3 \mathrm{~min})$ and precision $(2 \sigma, 0.5 \%)$ of the $\mathrm{NO}_{2}$-LOPAP instrument using recommended sampling solution (see Table 1) and instrument parameters (see Table 2, liquid flow $=0.35 \mathrm{ml} \mathrm{min}^{-1}$ ).

the sampling reagent $\left(0.2-0.4 \mathrm{ml} \mathrm{min}^{-1}\right)$ and the length of the absorption tubes (1.4-2.4 $\mathrm{m}$ ) the time resolution is in the range 3-6 min. With an optical path length of $2.4 \mathrm{~m}$ and a liquid flow of $0.4 \mathrm{ml} \mathrm{min}^{-1}$ a time resolution of $\sim 3 \mathrm{~min}$ and a detection limit of $\sim 2$ pptv is obtained. The detection limit is defined in the present study as two times the value of the standard deviation of the zero-air signal.

Since the lower limit of the measurement range is set by appropriate values of the above mentioned parameters, the upper limit of the measurement range can also be shifted during the data evaluation by shifting the absorption wavelength $\left(\lambda_{\text {abs }}\right)$ during the evaluation of the stored spectra. While highest sensitivity is obtained at the maximum absorption $\left(\lambda_{\text {abs }}=\sim 540 \mathrm{~nm}\right)$, the measurement range is expanded by more than one order of magnitude by shifting the absorption wavelength into the wings of the absorption band (e.g. $\lambda_{\text {abs }}=600 \mathrm{~nm}$ ). Thus, with an absorption length of $1.4 \mathrm{~m}, \mathrm{NO}_{2}$ concentrations up to $300 \mathrm{ppbv}$ can be measured. The precision of the instrument is defined in this study as the minimum detectable change of a measured signal and amounts to approximately $0.5 \%$ of the measured values (Fig. 6). The accuracy is obtained from the sum of all relative errors of $\sim 10 \%$ and the value the detection limit. The instrument parameters of the $\mathrm{NO}_{2}$-LOPAP are summarized in Table 2.

With the HONO-LOPAP instrument recently an optical length of $6 \mathrm{~m}$ was applied and thus a detection limit of only 0.2 pptv was reached for HONO (Kleffmann and Wiesen, 2008). Since the gas flow used for the $\mathrm{NO}_{2}$ instrument is ca. a factor of three smaller than that used for the HONO instrument, a minimum $\mathrm{NO}_{2}$ detection limit $<1$ pptv can be expected in the future for a time resolution of $8 \mathrm{~min}$.

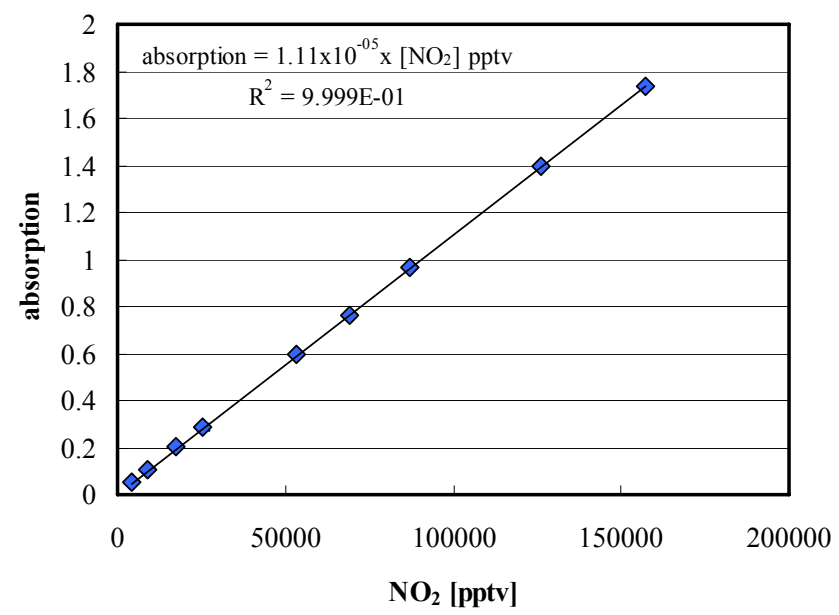

Fig. 7. $\mathrm{NO}_{2}$ concentration dependency of the LOPAP signal using recommended sampling solution (see Table 1) and instrument parameters (see Table 2, liquid flow $=0.35 \mathrm{ml} \mathrm{min}^{-1}$ ).

\subsection{Calibration}

The LOPAP instrument shows a linear response with the $\mathrm{NO}_{2}$ concentration for the entire measuring range (Fig. 7). Also for the calibration by liquid nitrite standards diluted in the Griess-Saltzman sampling solution a good linearity was obtained up to nitrite concentrations of $0.1 \mathrm{mg} \mathrm{l}^{-1}$. For higher nitrite concentrations non-linearity of the calibration was observed caused by losses, probably through the secondary reaction (8).

Caused by the linear response, the $\mathrm{NO}_{2}$ instrument can be calibrated simply by a two point calibration (zero air + calibration) with commercial available nitrite standards (accuracy $\pm 1 \%$ ) and by determination of the flow rates of the gas phase and of the stripping solution. A new calibration is only necessary when new reagents are prepared, which is ca. every 3 weeks for the used 101 containers. This is a significant simplification in comparison with other $\mathrm{NO}_{2}$ instruments, which usually are calibrated using $\mathrm{NO}_{2}$ calibration gas mixtures. These mixtures are known to have a low longterm stability. In addition, significant deviations from the concentrations specified by manufacturer are often observed. Alternatively, more stable NO calibration gas mixtures and ozone titration is used for commercial $\mathrm{NO}_{2}$ instruments, for which, however, an additional titration unit is necessary.

\subsection{Interferences}

In this section the interferences are specified as the interference signal measured as $\mathrm{NO}_{2}$ divided by the mixing ratio of the interfering compound in $\%\left(=100 \times\right.$ signal $\mathrm{NO}_{2}$ pptv/compound pptv). The interferences are listed in Table 3, either as interference in Channel 1 as defined above, or as "real interference" after subtraction of Channel 2 from Channel 1. All values given in this section correspond to a 
gas flow rate of $0.51 \mathrm{~min}^{-1}$, a liquid flow rate of $0.4 \mathrm{ml} \mathrm{min}^{-1}$ and a temperature of $15^{\circ} \mathrm{C}$. It is important to note that Channel 1 measures the sum of $97 \%$ of the $\mathrm{NO}_{2}$ plus potential interferences, while in Channel $23 \%$ of the $\mathrm{NO}_{2}$ plus interferences are determined. Assuming a small uptake of interfering compounds, their concentrations are almost constant in both coils, thus, the difference between the two channels corrected for the sampling efficiency of $\mathrm{NO}_{2}$ and the loss in the $\mathrm{HONO} / \mathrm{O}_{3}$ scrubber gives a measure of the true $\mathrm{NO}_{2}$ concentration.

\subsubsection{HONO interference}

A well known interference for the Griess-Saltzman method is ambient HONO (Milani and Dasgupta, 2001), which is also formed during $\mathrm{NO}_{2}$ detection as an intermediate in the Griess-Saltzman solution, reaction (6). Therefore an upstream stripping coil (" $\mathrm{HONO} / \mathrm{O}_{3}$ Scrubber") is placed in the $\mathrm{NO}_{2}$ instrument, which is operated with a solution of sulphanilamide in acetic acid (sulphanilamide $10 \mathrm{gl}^{-1}$, potassium indigo-trisulphonate $0.6 \mathrm{gl}^{-1}$, acetic acid $158 \mathrm{gl}^{-1}$ ). Acidic sulphanilamide solutions were already used as efficient HONO sampling solution in the HONO-LOPAP instrument (sampling efficiency >99\%) (Heland et al., 2001; Kleffmann et al., 2002, 2006). The HONO interference was tested with a pure HONO source, which is described in detail elsewhere (Kleffmann et al., 2004). A minimum interference of $0.092 \pm 0.090 \%$ could be observed in Channel 1, which is in good agreement with results from the HONO-LOPAP instrument. On the other hand, no interference could be observed in Channel 2, which can be explained by the high sampling efficiency of HONO in Channel 1 of the $\mathrm{NO}_{2}$ instrument. The remaining real HONO interference of ca. $0.1 \%$ represents even an upper limit, since the HONO source still could generate traces of $\mathrm{NO}_{2}$. In addition, even if true, the HONO interference can be completely neglected for typical $\mathrm{HONO} / \mathrm{NO}_{2}$ ratios of $<10 \%$ in the atmosphere.

\subsubsection{Ozone interference}

The ozone interference was tested with pure ozone mixtures, which were generated by the irradiation of pure $\mathrm{O}_{2}$ with an Hg lamp (Pen-ray) and dilution with synthetic air. Without the $\mathrm{HONO} / \mathrm{O}_{3}$ scrubber, a relatively large ozone interference (ca. 1\%) could be observed in Channel 1 (see Fig. 8), which can be explained by the oxidation of NEDA and the change in the absorption of the Griess-Saltzman solution. In Channel 2 there is no signal due to complete uptake of ozone in Channel 1 , so that the ozone interference could not be corrected by the two channel system. Initially, the value of $1 \%$ seemed to be small; however, measurements in remote regions, in which the ozone concentration can be up to three orders of magnitude higher than those of $\mathrm{NO}_{2}$, would be strongly affected by this ozone interference. Therefore, it was necessary to

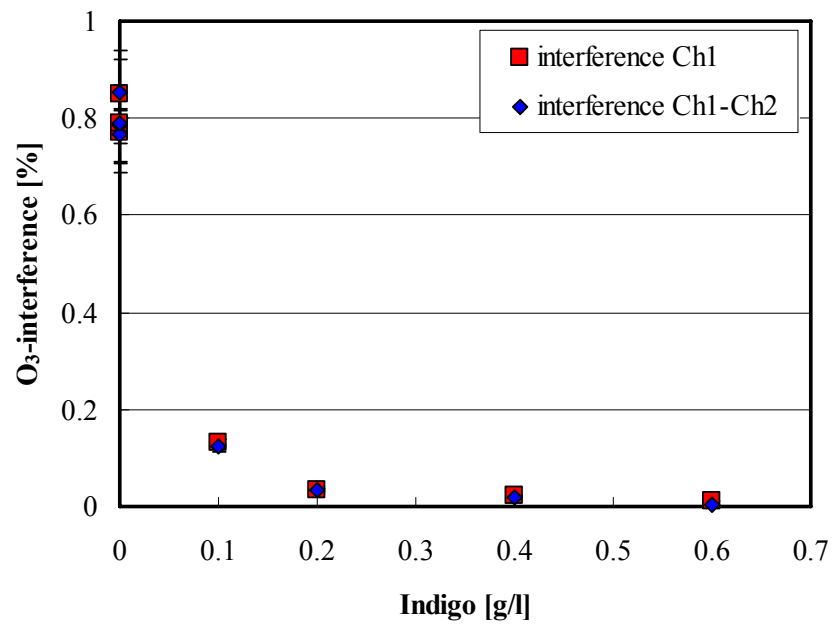

Fig. 8. $\mathrm{O}_{3}$ interference as a function of Indigo concentration $\left(\left[\mathrm{O}_{3}\right]=240 \mathrm{ppbv}\right)$.

efficiently remove ozone through the addition of a suitable reagent to the $\mathrm{HONO} / \mathrm{O}_{3}$ scrubber solution.

First tests with addition of potassium iodide (KI) to the $\mathrm{HONO} / \mathrm{O}_{3}$ scrubber solution were not successful, since $\mathrm{I}_{2}$ was formed in the reaction with $\mathrm{O}_{3}$, which partly degassed from the $\mathrm{HONO} / \mathrm{O}_{3}$ scrubber leading to additional light $\mathrm{ab}$ sorption and interference in Channel 1 of the instrument.

Alternatively, Indigo solution has been used for quantitative detection of $\mathrm{O}_{3}$ in aqueous solutions (Bader and Hoigné, 1981). Therefore, potassium Indigo-trisulphonate was chosen as scrubber solution and the ozone interference was tested as function of the Indigo concentration. A strong decrease of the $\mathrm{O}_{3}$ interference with increasing Indigo concentration is observed (Fig. 8). With an Indigo concentration of $0.6 \mathrm{~g} \mathrm{l}^{-1}$ an ozone interference of only $0.006 \%$ was observed. This interference is so low that even in clean air regions with very large $\mathrm{O}_{3} / \mathrm{NO}_{2}$ ratios only small corrections are necessary. Similar to HONO, the ozone uptake in the $\mathrm{HONO} / \mathrm{O}_{3}$ scrubber is independent of the liquid flow, so that for the routine operation of the $\mathrm{NO}_{2}$ instrument only small liquid flow rates $\left(0.05 \mathrm{ml} \mathrm{min}^{-1}\right)$ of the scrubber solution are necessary. As $\mathrm{HONO} / \mathrm{O}_{3}$ scrubber solution a mixture of sulphanilamide $\left(10 \mathrm{~g}^{-1}\right)$ and Indigo trisulphonate $\left(0.6 \mathrm{gl}^{-1}\right)$ in acetic acid $\left(158 \mathrm{~g} \mathrm{l}^{-1}\right)$ was selected. However, with this scrubber solution $\mathrm{NO}_{2}$ uptake of $4 \%$ was determined, which needs to be corrected during the data evaluation.

\subsubsection{Peroxyacetyl nitrate (PAN) interference}

The PAN interference was investigated in a $10801 \mathrm{smog}$ chamber and in which PAN was generated using an illuminated mixture of hydrogen peroxide $\left(\mathrm{H}_{2} \mathrm{O}_{2}\right)$, nitric oxide (NO), and propene in synthetic air. Caused by the low precision of the FTIR reference instrument for this complex reaction mixture, only an upper limit of the PAN interference of 
Table 3. Summary of the interferences tested for the $\mathrm{NO}_{2}$-LOPAP instrument.

\begin{tabular}{lll}
\hline component & $\begin{array}{l}\text { interference Ch1 } \\
{[\%]}\end{array}$ & $\begin{array}{l}\text { real interference } \\
\text { Ch1-Ch } 2[\%]\end{array}$ \\
\hline ozone & $0.0057 \pm(0.0005)$ & $0.0058 \pm(0.0007)$ \\
$\mathrm{H}_{2} \mathrm{O}_{2}$ & $0.0044 \pm 0.0002$ & $0.0040 \pm 0.0002$ \\
$\mathrm{HONO}$ & $0.092 \pm 0.090$ & $0.088 \pm 0.081$ \\
PAN & $<0.48$ & $<0.48$ \\
3-methyl-2-nitrophenol & $<0.0006$ & $<0.0006$ \\
2-nitrotoluene & $<0.00001$ & $<0.00001$ \\
glyoxal $\left(+\mathrm{NO}_{\mathrm{x}}\right)$ & $<0.11$ & $<0.11$ \\
toluene $\left(+\mathrm{NO}_{\mathrm{x}}\right)$ & $<0.04$ & $<0.04$ \\
$\alpha$-pinene $\left(+\mathrm{NO}_{\mathrm{x}}\right)$ & $<0.06$ & $<0.06$ \\
n-butane $\left(+\mathrm{NO}_{\mathrm{x}}\right)$ & $<0.04$ & $<0.04$ \\
propene $\left(+\mathrm{NO}_{\mathrm{x}}+\mathrm{H}_{2} \mathrm{O}_{2}\right)$ & $<0.01$ & $<0.01$ \\
Complex photosmog mixture (irradiation of & deviation $<4$ ppbv & deviation $<4$ ppbv \\
$\mathrm{NO}_{\mathrm{x}}$, glyoxal, n-butane, $\alpha$-pinene, toluene) $)$ & $($ DL of the FTIR) & $($ DL of the FTIR) \\
$\mathrm{NO}_{2}$ max. $=135$ ppbv & & \\
\hline
\end{tabular}

$<0.5 \%$ could be determined (see Table 3 ), i.e. the true PAN interference may be much lower.

Beside $\mathrm{HONO}, \mathrm{O}_{3}$, and PAN further interferences were tested in the laboratory in a 10801 smog chamber and are listed in Table 3. All interferences tested can be neglected under atmospheric conditions.

\subsection{Validation of the new instrument}

\subsubsection{Intercomparison in the atmosphere}

During the period 10-13 March 2007 an intercomparison campaign of the new $\mathrm{NO}_{2}$-LOPAP instrument was carried out with a commercial chemiluminescence instrument (ECO-Physics: AL $770 \mathrm{ppt} / \mathrm{PLC}$ 760) at the University of Wuppertal. The commercial instrument was equipped with a photolytic converter for the selective detection of $\mathrm{NO}_{2}$. For small to medium pollutant concentrations good agreement with the DOAS technique was observed for this instrument (Kurtenbach et al., 2001). Only for very high pollutant concentrations, as they arise in traffic tunnels, at kerbside stations or in laboratory and smog chamber studies, this instrument exhibits negative interferences, which are caused by photochemical reactions in the photolytic converter (Kurtenbach et al., 2001; Kleffmann et al., 2001; Bejan et al., 2006; Villena et al., 2011). However, for the relatively low pollutant concentrations arising during the intercomparison campaign these interferences were neglected. The sampling site was on the balcony of the 5th floor of a building of the University of Wuppertal.

During all the period of the intercomparison, very good agreement was observed between both instruments in terms of absolute concentrations (see Figs. 9, 10) and temporal variation of the concentration (Fig. 9). Only for very fast variations of the $\mathrm{NO}_{2}$ concentration deviations were ob-

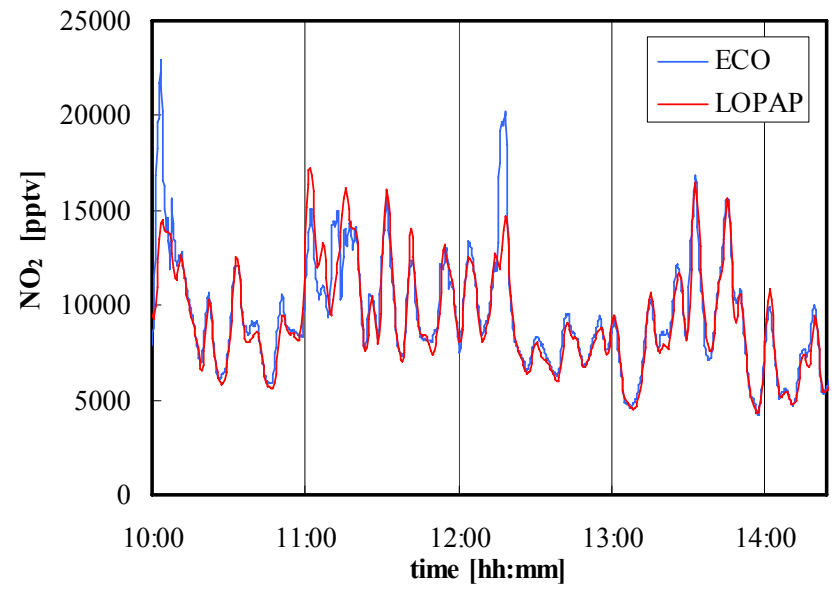

Fig. 9. Selected time interval of the $\mathrm{NO}_{2}$ concentrations measured with the $\mathrm{NO}_{2}$-LOPAP and the Eco-Physics instruments during the ambient intercomparison campaign at the University of Wuppertal.

served due to the smaller time resolution of the LOPAP instrument (e.g. Fig. 9, ca. 10:00 and ca. 12:15 LT). Furthermore, it is well-known that due to the temporally shifted measurements of $\mathrm{NO}$ and $\mathrm{NO}_{\mathrm{x}}$ with the one channel ECO Physics instrument, short term variations of pollutants often lead to unrealistic strong concentration peaks for this instrument. From a correlation plot of the $5 \mathrm{~min}$ averaged data a mean deviation between both instruments of only $2 \%$ has been determined (Fig. 10), which is clearly within the errors of both methods. If only the $\mathrm{NO}_{2}$ data $<6 \mathrm{ppbv}$ are used for the correlation, a similar good agreement compared to the one shown in Fig. 10 is observed $(\mathrm{LOPAP}=0.998 \times \mathrm{ECO}+0.19 \mathrm{ppbv})$.

In conclusion, the LOPAP instrument could be successfully validated in the atmosphere under moderately polluted 
conditions with the help of a commercial chemiluminescence instrument with photolytic converter. However, since the LOPAP instrument was yet not used under remote conditions, an intercomparison at lower $\mathrm{NO}_{2}$ level in the atmosphere is still an open task.

The LOPAP instrument was used as a two channel system for the correction of unknown interferences during the intercomparison campaign. However, during the whole campaign, only a small signal in the interference channel (Channel 2) was observed, which corresponded exactly to the loss of $\mathrm{NO}_{2}$ from Channel 1 caused by the sampling efficiency of the instrument. During this campaign the instrument had a sampling efficiency of $95 \pm 1 \%$ (old stripping coil) and an average value of the ratio Channel 2/Channel 1 of $4.7 \pm 1.2 \%$ was determined. Thus, in between the experimental errors no interferences could be observed in the real atmosphere.

\subsubsection{Intercomparison in a smog chamber}

Besides the intercomparison in the atmosphere the new $\mathrm{NO}_{2}$ LOPAP was also compared with the spectroscopic FTIR technique under complex photosmog conditions in a 10801 smog chamber whose detailed description can be found elsewhere (Barnes et al., 1994). In this experiment a mixture of $\mathrm{NO}$ and different hydrocarbons was irradiated with UV light, leading to a conversion of $\mathrm{NO}$ into $\mathrm{NO}_{2}$ by $\mathrm{O}_{3}$ photochemically formed. Also in these experiments excellent agreement was observed between both instruments, whereas three other commercial instruments showed significant positive (luminol technique) and negative (chemiluminescence technique with photolytic converter) interferences. The deviation between the $\mathrm{NO}_{2}$-LOPAP and the FTIR was $<4$ ppbv for a $\mathrm{NO}_{2}$ concentration range $0-135 \mathrm{ppbv}$, which is within the experimental errors of both instruments (DL of the FTIR ca. 4 ppbv). Details of this intercomparison will be presented elsewhere (Villena et al., 2011). Similar to the field intercomparison, the signal in Channel 2 of the instrument again exactly represented the loss of $\mathrm{NO}_{2}$ from Channel 1 caused by the sampling efficiency, which was $97 \%$ in the smog chamber experiments. If these results are also confirmed for remote measurement conditions, the $\mathrm{NO}_{2}$-LOPAP instrument could be designed as an even simpler one channel instrument in the future.

\section{Conclusions}

A new instrument for the sensitive measurement of $\mathrm{NO}_{2}$ by wet sampling and photometric detection has been developed and successfully tested. The instrument shows a linear response with a measurement range from the detection limit up to $300 \mathrm{ppbv}$, which can be calibrated absolutely by commercial nitrite standards. The instrument has a detection limit of 2 pptv for a time resolution of $3 \mathrm{~min}$, which can be fur-

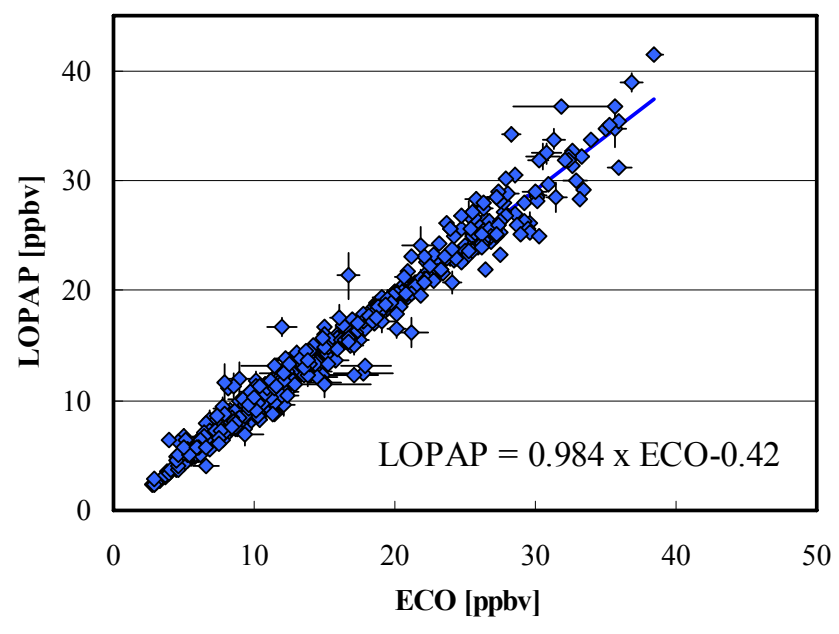

Fig. 10. Correlation of all $5 \mathrm{~min}$ averaged $\mathrm{NO}_{2}$ data of the $\mathrm{NO}_{2}-$ LOPAP against the Eco- Physics instrument. The error bars represent only the precision of the instruments. A weighted orthogonal regression analysis was used, for which the errors of both instruments were considered (Brauers and Finlayson-Pitts, 1997).

ther reduced to $<1 \mathrm{pptv}$ for lower time resolution. Known interferences against $\mathrm{O}_{3}$ and $\mathrm{HONO}$ were successfully suppressed by an additional scrubber for both gases. All other interferences tested can be neglected, both, in the atmosphere but also under complex conditions in a smog chamber. The instrument was validated by intercomparison with a commercial chemiluminescence instrument with photolytic $\mathrm{NO}_{2}$ converter in an urban atmosphere and with the FTIR technique in a smog chamber. Excellent agreement was obtained under all conditions applied.

Acknowledgements. The authors would like to thank the German Environment Foundation (Deutsche Bundesstiftung Umwelt DBU, Contract No. 24171) for financial and QUMA Elektronik \& Analytik GmbH, Wuppertal, Germany, for continuous technical support during the development of the $\mathrm{NO}_{2}$-LOPAP instrument. In addition, DuPont is gratefully acknowledged for the license agreement for the scientific use of the Teflon AF.

Edited by: F. Boersma

\section{References}

Adema, E. H.: Ozone interference in the determination of nitrogen dioxide by a modified manual Saltzman method, Anal. Chem., 51, 1002-1006, 1979.

Alfassi, Z. B., Huie, R. E., and Neta, P.: Substituent effects on the rates of one-electron oxidation of phenols by the radicals $\mathrm{ClO}_{2}$, $\mathrm{NO}_{2}$, and $\mathrm{SO}_{3}^{-}$, J. Phys. Chem., 90, 4156-4158, 1986.

Alvarez, R., Weilenmann, M., and Favez, J. Y.: Evidence of increased mass fraction of $\mathrm{NO}_{2}$ within real-world $\mathrm{NO}_{\mathrm{x}}$ emissions of modern light vehicles-derived from a reliable online measuring method, Atmos. Environ., 42, 4699-4707, 2008. 
Ammann, M., Rössler, E., Strekowski, R., and George, C.: Nitrogen dioxide multiphase chemistry: uptake kinetics on aqueous solutions containing phenolic compounds, Phys. Chem. Chem. Phys., 7, 2513-2518, 2005.

AQEG, 2007: Trends in primary nitrogen dioxide in the UK, Report of the UK Air Quality Expert Group, AQEG, Prepared for the department for environment food and rural affairs, the Scottish executive, the Welsh assembly and the department of the environment in northern Ireland, Defra Publications, London, 2007.

Bader, H. and Hoigné, J.: Determination of ozone in water by the indigo method, Water Res., 15, 449-456, 1981.

Barnes, I., Becker, K. H., and Mihalopoulos, N.: An FT-IR product study of the photo-oxidation of dimethyl disulfide, J. Atmos. Chem., 18, 267-289, 1994.

Bejan, I., Abd El Aal, Y., Barnes, I., Benter, T., Bohn, B., Wiesen, P., and Kleffmann, J.: The photolysis of ortho-nitrophenols: A new gas phase source of HONO, Phys. Chem. Chem. Phys., 8, 2028-2035, 2006.

Brauers, T. and Finlayson-Pitts, B. J.: Analysis of relative rate measurements, Int. J. Chem. Kinet., 29, 665-672, 1997.

Brunekreef, B.: $\mathrm{NO}_{2}$ : The gas that won't go away, Clin. Exp. Allergy, 31, 1170-1172, 2001.

Carslaw, D. C.: Evidence of an increasing $\mathrm{NO}_{2} / \mathrm{NO}_{\mathrm{x}}$ emissions ratio from road traffic emissions, Atmos. Environ., 39, 4793-4802, 2005.

Carslaw, D. C. and Beevers, S. D.: New directions: Should road vehicle emissions legislation consider primary $\mathrm{NO}_{2}$ ?, Atmos. Environ., 38, 1233-1234, 2004.

Carslaw, D. C. and Beevers, S. D.: Estimations of road vehicle primary $\mathrm{NO}_{2}$ exhaust emission fractions using monitoring data in London, Atmos. Environ., 39, 167-177, 2005a.

Carslaw, D. C. and Beevers, S. D.: Development of an urban inventory for road transport emissions of $\mathrm{NO}_{2}$ and comparison with estimates derived from ambient measurements, Atmos. Environ., 39, 2049-2049, 2005 b.

Carslaw, D. C. and Carslaw, N.: Detecting and characterising small changes in urban nitrogen dioxide concentrations, Atmos. Environ., 41, 4723-4733, 2007.

Carslaw, D. C., Beevers, S. D., and Bell, M. C.: Risks of exceeding the hourly EU limit value for nitrogen dioxide resulting from increased road transport emissions of primary nitrogen dioxide, Atmos. Environ., 41, 2073-2082, 2007.

Cheung, J. L., Li, Y. Q., Boniface, J., Shi, Q., Davidovits, P., Worsnop, D. R., Jayne, J. T., and Kolb, C. E.: Heterogeneous interactions of $\mathrm{NO}_{2}$ with aqueous surfaces, J. Phys. Chem. A, 104, 2655-2662, 2000.

Crutzen, P. J.: The role of $\mathrm{NO}$ and $\mathrm{NO}_{2}$ in the chemistry of the troposphere and stratosphere, Ann. Rev. Earth Planet. Sci., 7, 443472, 1979.

Dari-Salisburgo, C., Di Carlo, P., Giammaria, F., Kajii, Y., and D'Altorio, A.: Laser induced fluorescence for $\mathrm{NO}_{2}$ measurements: Observations at a central Italy background site, Atmos. Environ., 43, 970-977, 2009.

Delfino, R. J., Staimer, N., Tjoa, T., Gillen, D., Kleinman, M. T., Sioutas, C., and Cooper, D.: Personal and ambient air pollution exposures and lung function decrements in children with asthma, Environ. Health Persp., 116, 550-558, 2008.

Demerjian, K. L.: A review of national monitoring networks in North America, Atmos. Environ., 34, 1861-1884, 2000.
Dunlea, E. J., Herndon, S. C., Nelson, D. D., Volkamer, R. M., San Martini, F., Sheehy, P. M., Zahniser, M. S., Shorter, J. H., Wormhoudt, J. C., Lamb, B. K., Allwine, E. J., Gaffney, J. S., Marley, N. A., Grutter, M., Marquez, C., Blanco, S., Cardenas, B., Retama, A., Ramos Villegas, C. R., Kolb, C. E., Molina, L. T., and Molina, M. J.: Evaluation of nitrogen dioxide chemiluminescence monitors in a polluted urban environment, Atmos. Chem. Phys., 7, 2691-2704, doi:10.5194/acp-7-2691-2007, 2007.

Edner, H., Ragnarson, P., Spännare, S., and Svanberg, S.: Differential optical absorption spectroscopy (DOAS) system for urban atmospheric pollution monitoring, Appl. Phys, 32, 327-333, 1993.

EEA Report, Air Pollution in Europe 1990-2004, European environment agency. Report 2/2007. ISSN 1725-9177, Copenhagen, Denmark, 2007.

EU Directive 96/62/EC of 27 September, 1996, On ambient air quality assessment and management (the framework directive). From the official Journal of the European Communities 21.11.1996, En Series, L296/55.

EU Directive 98/69/EC of 13 October, 1998, Relating to measures to be taken against air pollution by emissions from motor vehicles and amending Council Directive 70/220/EEC. From the official Journal of the European Communities, 28.12.1998, En Series, L350/1.

EU Directive 99/30/EC of 22 April, 1999, Relating to limit values for sulphur dioxide, nitrogen dioxide and oxides of nitrogen, particulate matter and lead in ambient air (The First Daughter Directive) From the official Journal of the European Communities 29.06.1999, En Series, L163/41.

EU Directive 99/96/EC of 13 December 1999, On the approximation of the laws of the Member states relating to measures to be taken against the emission of gaseous and particulate pollutants from compression ignition engines for use in vehicles, and the emission of gaseous pollutants from positive ignition engines fuelled with natural gas or liquefied petroleum gas for use in vehicles and amending Council Directive 88/77/EEC, From the official Journal of the European Communities, 13.12.1999, En Series, L 44/1.

European Standard, EN 14211, 2005: Ambient air quality - Standard method for the measurement of the concentration of nitrogen dioxide and nitrogen monoxide by chemiluminescence.

Fehsenfeld, F. C., Drummond, J. W., Roychowdhury, U. K., Galvin, P. J., Williams, E. J., Buhr, M. P., Parrish, D. D., Hübler, G., Langford, A. O., Calvert, J. G., Ridley, B. A., Grahek, F., Heikes, B. G., Kok, G. L., Shetter, J. D., Walega, J. G., Elsworth, C. M., Norton, R. B., Fahey, D. W., Murphy, P. C., Hovermale, C., Mohnen, V. A., Demerjian, K. L., Mackay, G. I., and Schiff, H. I.: Intercomparison of $\mathrm{NO}_{2}$ measurement techniques, J. Geophys. Res., 95(D4), 3579-3597, 1990.

Finlayson-Pitts, B. J. and Pitts J. N. Jr.: Chemistry of the upper and lower atmosphere: Theory, Experiments and Applications, Academic Press: New York, 2000.

Fontjin, A., Sabadell, A. J., and Ronco, R. J.: Homogeneous chemiluminescence measurement of nitric oxide with ozone, Anal. Chem., 42, 575-579, 1970.

Frenzel, A., Kutsuna, S., Takeuchi, K., and Ibusuki, T.: Solubility and reactivity of Peroxyacetyl Nitrate (PAN) in dilute aqueous solutions and in sulphuric acid, Atmos. Environ., 34, 3641-3644, 2000.

Fuchs, H., Dubé, W. P., Lerner, B. M., Wagner, N. L., Williams, E. 
J., and Brown, S. S.: A sensitive and versatile detector for atmospheric $\mathrm{NO}_{2}$ and $\mathrm{NO}_{\mathrm{x}}$ based on blue diode laser cavity ring-down spectroscopy, Environ. Sci. Technol., 43, 7831-7836, 2009.

Fuchs, H., Ball, S. M., Bohn, B., Brauers, T., Cohen, R. C., Dorn, H.-P., Dubé, W. P., Fry, J. L., Häseler, R., Heitmann, U., Jones, R. L., Kleffmann, J., Mentel, T. F., Müsgen, P., Rohrer, F., Rollins, A. W., Ruth, A. A., Kiendler-Scharr, A., Schlosser, E., Shillings, A. J. L., Tillmann, R., Varma, R. M., Venables, D. S., Villena Tapia, G., Wahner, A., Wegener, R., Wooldridge, P. J., and Brown, S. S.: Intercomparison of measurements of $\mathrm{NO}_{2}$ concentrations in the atmosphere simulation chamber SAPHIR during the $\mathrm{NO}_{3}$ Comp campaign, Atmos. Meas. Tech., 3, 21-37, doi:10.5194/amt-3-21-2010, 2010.

Garnica, R. M., Appel, M. F., Eagan, L., McKeachie, J. R., and Benter, Th.: A REMPI method for the ultrasensitive detection of $\mathrm{NO}$ and $\mathrm{NO}_{2}$ using atmospheric pressure laser ionization mass spectrometry, Anal. Chem, 72, 5639-5646, 2000.

Gherman, T., Venables, D., Vaughan, S., Orphal, J., and Ruth, A.: Incoherent broadband cavity-enhanced absorption spectroscopy in the near-ultraviolet application to $\mathrm{HONO}$ and $\mathrm{NO}_{2}$, Environ. Sci. Technol., 42, 890-895, 2008.

Grasshoff, K., Ehrhardt, M., and Kremling, K.: Methods of Seawater Analysis, 2 Edn., Verlag Chemie: Weinheim, p. 140, 1983.

Grice, S., Stedman, J., Kent, A., Hobson, M., Norris, J., Abbott, J., and Cooke, S.: Recent trends and projections of primary $\mathrm{NO}_{2}$ emissions in Europe, Atmos. Environ., 43, 2154-2167, 2009.

Gregory, G. L., Hoell, J. M., Carroll, M. A., Ridley, B. A., Davis, D. D., Bradshaw, J., Rodgers, M. O., Sandholm, S. T., Schiff, H. I., Hastie, D. R., Karecki, D. R., Mackay, G. I., Harris, G. W., Torres, A. L., and Fried, A.: An intercomparison of airborne nitrogen dioxide instruments, J. Geophys. Res., 95, 10103-10127, 1990.

Hargrove, J., Wang, L., Muyskens, K., Muyskens, M., Medina, D., Zaide, S., and Zhang, I.: Cavity ring-down spectroscopy of ambient $\mathrm{NO}_{2}$ with quantification and elimination of interferences, Environ. Sci. Technol., 40, 7868-7873, 2006.

Heland, J., Kleffmann, J., Kurtenbach, R., and Wiesen P.: A new instrument to measure gaseous nitrous acid (HONO) in the atmosphere, Environ. Sci. Technol., 35, 3207-3212, 2001.

Herndon, S. C., Shorter, J. H., Zahniser, M., Nelson, D. D., Jayne, J. J., Brown, R. C., Miake-Lye, R. C., Waitz, I., Silva, P., Lanni, T., Demerjian, K., and Kolb, C.: $\mathrm{NO}$ and $\mathrm{NO}_{2}$ emission ratios measured from in-use commercial aircraft during taxi and takeoff, Environ. Sci. Technol, 38, 6078-6084, 2004.

Huygens, C. and Lanting R. W.: Short communications on the Saltzman factor, Atmos. Environ., 9, 1027-1029, 1975.

Jarvis, D. L., Leaderer, B. D., Chinn, S., and Burney, P. G.: Indoor nitrous acid and respiratory symptoms and lung function in adults, Thorax, 60, 474-479, 2005.

Jenkin, M. E., Utembe, S. R., and Derwent, R. G.: Modelling the impact of elevated primary $\mathrm{NO}_{2}$ and $\mathrm{HONO}$ emissions on regional scale oxidant formation in the UK, Atmos. Environ., 42, 323-336, 2008

Kebabian, P. L., Herndon, S. C., and Freedman, A.: Detection of nitrogen dioxide by cavity attenuated phase shift spectroscopy, Anal. Chem., 77, 724-728, 2005.

Kebabian, P. L., Wood, E. C., Herndon, S. C., and Freedman, A.: A practical alternative to chemiluminescence-based detection of nitrogen dioxide: Cavity Attenuated Phase Shift Spectroscopy,
Environ. Sci. Technol., 42, 6040-6045, 2008.

Keuken, M., Roemer, M., and van den Elshout, S.: Trend Analysis of Urban $\mathrm{NO}_{2}$ Concentrations and the Importance of Direct $\mathrm{NO}_{2}$ Emissions versus Ozone/ $\mathrm{NO}_{\mathrm{x}}$ Equilibrium, Atmos. Environ., 43, 4780-4783, 2009.

Kleffmann, J. and Wiesen, P.: Technical Note: Quantification of interferences of wet chemical HONO LOPAP measurements under simulated polar conditions, Atmos. Chem. Phys., 8, 6813-6822, doi:10.5194/acp-8-6813-2008, 2008.

Kleffmann, J., Heland, J., Kurtenbach, R., Lörzer, J. C., Wiesen, P., Ammann M., Gutzwiller, L., Rodenas Garcia, M., Pons, M., Wirtz, K., Scheer, V., and Vogt, R.: HONO emissions from a diesel engine, Proceedings of the 94th Annual Conference and Exhibition of the Journal of the Air \& Waste Management Association, paper 239, 2001.

Kleffmann, J., Heland, J., Kurtenbach, R., Lörzer, J. C., and Wiesen, P.: A new instrument (LOPAP) for the detection of nitrous acid (HONO), Environ. Sci. Pollut. Res., 9(4), 48-54, 2002.

Kleffmann, J., Benter, T., and Wiesen, P.: Heterogeneous reaction of nitric acid with nitric oxide on glass surfaces under simulated atmospheric conditions, J. Phys. Chem. A, 108, 5793-5799, 2004.

Kleffmann, J., Lörzer, J. C., Wiesen, P., Kern, C., Trick, S., Volkamer, R., Rodenas, M., and Wirtz, K: Intercomparisons of the DOAS and LOPAP techniques for the detection of nitrous acid (HONO) in the atmosphere, Atmos. Environ., 40, 3640-3652, 2006.

Kleffmann J., Gavriloaiei, T., Elshorbany, Y., Ródenas, M., and Wiesen, P.: Detection of nitric acid $\left(\mathrm{HNO}_{3}\right)$ in the atmosphere using the LOPAP technique, J. Atmos. Chem., 58, 131-149, 2007.

Kley, D. and McFarland M.: Chemiluminescence detector for NO and $\mathrm{NO}_{2}$, Atmos. Tech., 12, 63-69, 1980.

Komiyama, H. and Inoue, H.: Absorption of nitrogen oxides into water, Chem. Eng. Sci., 35, 154-161, 1980.

Kurtenbach, R., Becker, K. H., Gomes, J. A. G., Kleffmann, J., Lörzer, J. C., Spittler, M., Wiesen, P., Ackermann, R., Geyer, A., and Platt, U.: Investigation of emissions and heterogeneous formation of HONO in a road traffic tunnel, Atmos. Environ., 35, 3385-3394, 2001.

Li, Y. Q., Demerjian, K. L., Zahniser, M. S., Nelson, D. D., McManus, J. B., and Herndon, S. C.: Measurement of formaldehyde, nitrogen dioxide, and sulfur dioxide at Whiteface mountain using a dual tunable laser system, J. Geophys. Res., 109, D16S08, doi:10.1029/2003JD004091, 2004.

Matsumoto J., Hirokawa J., Akimoto H., and Kajii Y.: Direct measurement of $\mathrm{NO}_{2}$ in the marine atmosphere by laser-induced fluorescence technique, Atmos. Environ., 35, 2803-2814, 2001.

Matsumoto, J., Kosugi, N., Nishiyama, A., Isozaki, R., Sadanaga, Y., Kato, S., Bandow, H., and Kajii, Y.: Examination on photostationary state of $\mathrm{NO}_{x}$ in the urban atmosphere in Japan, Atmos. Environ., 40, 3230-3239, 2006.

Mazurenka, M. I., Fawcett, B. L., Elks, J. M. F., Shallcross, D. E., and Orr-Ewing, A. J.: 410-nm diode laser cavity ring-down spectroscopy for trace detection of $\mathrm{NO}_{2}$, Chem. Phys. Lett., 367, 1-9, 2003.

McKeachie, J. R., Van der Veer, W. E., Short, L. C., Garnica, R. M., Appel, M. F., and Benter, Th.: Selective ultra-trace detection of $\mathrm{NO}$ and $\mathrm{NO}_{2}$ in complex gas mixtures using broad-bandwidth 
REMPI mass spectrometry, Analyst, 126, 1221-1228, 2001.

Milani, M. R. and Dasgupta, P. K.: Measurement of nitrogen dioxide and nitrous acid using gas-permeable liquid core waveguides, Anal. Chim. Acta, 431, 169-180, 2001.

Mol, W. J. A., Van Hooydonk, P. R., and De Leeuw, F. A. A. M.: European exchange of monitoring information and state of the air quality in 2006, European Topic Centre on Air and Climate Change (ETC / ACC), European Environment Agency, The Netherlands, Technical paper 2008/1.

Murphy, D. M. and Fahey, D. W.: Mathematical treatment of the wall loss of a trace species in denuder and catalytic-converter tubes, Anal. Chem., 59(23), 2753-2759, 1987.

Osthoff, H. D., Brown, S. S., Ryerson, T. B., Fortin, T. J., Lerner, B. M., Williams, E. J., Pettersson, A., Baynard, T., Dubé, W. P., Ciciora, S. J., and Ravishankara, A. R.: Measurement of atmospheric $\mathrm{NO}_{2}$ by pulsed cavity ring-down spectroscopy, J. Geophys. Res., 111, D12305, doi:10.1029/2005JD006942, 2006.

Platt, U., Perner, D., and Pätz, W.: Simultaneous measurement of atmospheric $\mathrm{CH}_{2} \mathrm{O}, \mathrm{O}_{3}$ and $\mathrm{NO}_{2}$ by differential optical absorption, J. Geophys. Res, 84, 6329-6335, 1979.

Pryor, W. A. and Lightsey, J. W.: Mechanisms of nitrogen dioxide reactions: Initiation of lipid peroxidation and the production of nitrous acid, Science, 214, 435-437, 1981.

Ridley, B. A. and Howlett, L. C.: An instrument for nitric oxide measurements in the stratosphere, Rev. Sci. Instrum., 45, 742746, 1974.

Rohrer, F., Bohn, B., Brauers, T., Brning, D., Johnen, F.-J., Wahner, A., and Kleffmann, J.: Characterisation of the photolytic HONO-source in the atmosphere simulation chamber SAPHIR, Atmos. Chem. Phys., 5, 2189-2201, doi:10.5194/acp-5-21892005, 2005.

Saltzman, B. E.: Colorimetric microdetermination of nitrogen dioxide in the atmosphere, Anal. Chem., 26, 1949-1955, 1954.

Samoli, E., Aga, E., Touloumi, G., Nisiotis, K., Forsberg, B., Lefranc, A., Pekkanen, J., Wojtyniak, B., Schindler, C., Niciu, E., Brunstein, R., Dodic Fikfak, M., Schwartz, J., and Katsouyanni, K.: Short-term effects of nitrogen dioxide on mortality: an analysis within the APHEA project, Eur. Respir. J., 27, 1129-1137, 2006.

Seinfeld, J. H. and Pandis, S. N.: Atmospheric chemistry and physics: From air pollution to climate change, 2nd edition, John Wiley \& Sons, Inc., New Jersey, 2006.
Spicer, C. W., Billick, I. H., and Yangagisawa, Y.: Nitrous acid interference with passive $\mathrm{NO}_{2}$ measurement methods and the impact on indoor $\mathrm{NO}_{2}$ data, Indoor Air, 11, 156-161, 2001.

Squadrito, G. L. and Postlethwait, E. M.: On the hydrophobicity of nitrogen dioxide: Could there be a "lens" effect for $\mathrm{NO}_{2}$ reaction kinetics?, Nitric Oxide, 21, 104-109, 2009.

Thornton, J. A., Wooldridge, P. J., and Cohen, R. C.: Atmospheric $\mathrm{NO}_{2}$ : In situ Laser-Induced Fluorescence detection at parts per trillion mixing ratios, Anal. Chem., 72, 528-539, 2000.

Thornton, J. A., Wooldridge, P. J., Cohen, R. C., Williams, E. J., Hereid, D., Fehsenfeld, F. C., Stutz, J., and Alicke, B.: Comparison of in situ and long path measurements of $\mathrm{NO}_{2}$ in urban plumes, J. Geophys. Res., 108, D4496, doi:10.1029/2003JD003559, 2003.

Van Strien, R. T., Gent, J. F., Belanger, K., Triche, E., Bracken, M. B., and Leaderer, B. P.: Exposure to $\mathrm{NO}_{2}$ and nitrous acid and respiratory symptoms in the first year of life, Epidemiology, 15(4), 471-478, 2004.

Vestreng, V., Ntziachristos, L., Semb, A., Reis, S., Isaksen, I. S. A., and Tarrasón, L.: Evolution of $\mathrm{NO}_{\mathrm{x}}$ emissions in Europe with focus on road transport control measures, Atmos. Chem. Phys., 9, 1503-1520, doi:10.5194/acp-9-1503-2009, 2009.

Villena, G., Bejan, I., Kurtenbach, R., Wiesen, P., and Kleffmann, $\mathrm{J}$.: Interferences of commercial $\mathrm{NO}_{2}$ instruments in the urban atmosphere and in a smog chamber, Atmos. Meas. Tech. Discuss., 4, 4269-4293, doi:10.5194/amtd-4-4269-2011, 2011.

Wendel, G. J., Stedman, D. H., and Cantrell, C. A.: Luminol-based nitrogen dioxide detector, Anal. Chem., 55, 937-940, 1983.

Winer, A. M., Peters, J. W., Smith, J. P., and Pitts, J. N. Jr.: Response of commercial chemiluminescence $\mathrm{NO}-\mathrm{NO}_{\mathrm{x}}$ analyzers to other nitrogen-containing compounds, Environ. Sci. Technol., 8, 1118-1121, 1974.

Wu, T., Zhao, W., Chen, W., Zhang, W., and Gao, X.: Incoherent broadband enhanced absorption spectroscopy for in situ measurements of $\mathrm{NO}_{2}$ with a blue light emitting diode, Appl. Phys. B, 94, 85-94, 2009.

Yao, W., Byrne, R. H., and Waterbury, R. D.: Determination of nanomolar concentrations of nitrite and nitrate in natural waters using long path length absorbance spectroscopy, Environ. Sci. Technol., 32, 2646-2649, 1998. 